\title{
CONTINGENT VALUATION: PAST, PRESENT AND FUTURE
}

\author{
David Hoyos, Petr Mariel*
}

\begin{abstract}
:
This paper summarizes the long history of the contingent valuation method, stressing the important dates and events that influenced its economic applications. It reviews the economic theory of contingent valuation, highlights the related survey design, alludes to the econometrics methodology involved and discusses the validity and reliability of this method. In summary, this paper presents the state of the art of a method that has been applied in the economic valuation of natural resources for many decades.
\end{abstract}

Keywords: economic valuation, stated preference information

JEL Classification: Q510

\section{Introduction}

The economic valuation of natural resources using stated preference (SP) information has come to be known as contingent valuation (CV), given that the value estimates obtained are contingent on the information previously provided to the respondent in the survey. $\mathrm{CV}$ is deeply rooted in welfare economics: to be precise, in the neoclassical concept of economic value under the framework of individual utility maximisation. CV surveys are capable of directly obtaining a monetary (Hicksian) measure of welfare associated with a discrete change in the provision of an environmental good, by substituting one good for another or the marginal substitution of different attributes of an existing good. There are some other terms that have been used for the value estimates derived from stated preference information, depending on the elicitation format used: discrete choice experiment, bidding game, open-ended question, choicebased conjoint analysis, contingent ranking, single- or double-bounded dichotomous choice, paired comparisons, payment card, etc.

The history of the contingent valuation method (CVM) can be broadly divided into three periods. In the first period (1943-1989), covering the origins of the method up to the Exxon Valdez accident, the CVM conforms as an alternative to revealed preference methods, such as the travel cost method (TCM), especially in the field of

* David Hoyos and Petr Mariel, Department of Applied Economics III, University of the Basque Country, Lehendakari Agirre 83, 48015 Bilbao, Spain (david.hoyos@ehu.es; petr.mariel@ehu. es). The authors are grateful to the Department of Education of the Basque Government for grants IT-334-07 (UPV/EHU Econometrics Research Group) and SEJ2007-61362 (from the Spanish Ministerio de Educación and FEDER). 
outdoor recreation. In the second period (1989-1992), the extensive debate following the Exxon Valdez oil spill stimulated further research on the theory and empirics of stated preferences for non-market valuation techniques. Finally, from 1992 onwards, the CVM has been consolidated as a non-market valuation method, being accepted at both an academic and a political level.

Back in the 1940s, Bowen (1943) and Ciriacy-Wantrup (1947) were the first to propose the use of a public opinion survey as a valid instrument to value public goods, based on the idea that voting could be the closest substitute for consumer choice. In what is often considered the first book on environmental and resource economics, Resource Conservation: Economics and Policy, Ciriacy-Wantrup (1952) defends the use of "direct interview methods". However, influential economists, such as Samuelson and Friedman, mistrusted survey responses on the grounds of strategic behaviour and non-rationality of responses (Carson and Hanemann, 2005).

Outdoor recreation was the main force behind early empirical developments of the CVM in this period. During the 1950s and 1960s, managers of the U.S. National Park and U.S. Forest Services required information on people's preferences and willingness to pay (WTP) for these public services. Similarly, the U.S. agencies building water projects at that time were interested in recreational benefits in order to make these projects more attractive under the cost-benefit analysis framework. The first economist to implement a CV survey was Davis (1963a, 1963b), in his research on the economic value of recreation in the Maine woods. The author argues that real market behaviour could be simulated in a survey by describing alternative facilities available to the public and then eliciting the highest possible bid. A few years later, CVM and TCM estimates were for the first time successfully tested for convergent validity (Knetsch and Davis, 1966). Meanwhile, surveys were used to elicit information about preferences for public goods in the fields of health and transport economics by Michael Jones-Lee and Jordan Louviere, respectively. Also, the range of applications spanned different types of environmental goods, such as recreation, air quality, congestion, waste management and others.

Some developments regarding the CVM's ability to measure non-use values helped to give the methodology substantial advances in the late 1960s. In fact, it was shown that WTP estimates could include potentially important non-use values: option values (Weisbrod, 1964), existence values (Krutilla, 1967) and quasi-option values (Arrow and Fisher, 1974). Existence or passive-use values were found to be significant in environmental valuation since many respondents were showing positive WTP values for environmental quality changes that were not reflected in any observable behaviour. In Krutilla (1967), considered as one of the most influential papers in environmental economics, the author highlights the importance of irreversibility in environmental decision making and discusses the possibility that non-use values constitute a main component of the total economic value of an environmental good (Portney, 1994). Of course, not including these values would give wrong signals to policymakers and the only methodology available to capture them was CVM. Furthermore, the theory of existence value and quasi-option value had a strong influence on the management of unique and threatened natural resources (Aldy and Krupnick, 2009).

From a methodological point of view, it is important to highlight the paper published by Bishop and Heberlein (1979), which was the first to incorporate the dichotomous 
format in CV surveys. The dichotomous format (also known as referendum or closedended) gained considerable acceptance because of its incentive compatibility (i.e. it induces respondents to reveal their true preferences) and its substantial simplification of the cognitive task faced by respondents. The theoretical formulation of the CVM corresponds to Hanemann (1984), Cameron and James (1987) and Cameron (1988). The approaches are dual to each other: while the former formulates the problem through two indirect utility functions, known as the difference in indirect utility functions model, the latter interprets the response to a CV survey as a comparison between the bid amount and the respondent's true underlying value, known as the variation function model (McConnell, 1990).

The methodology was further refined and gained considerable political acceptance in the United States in the 1970s and 1980s given that it was accepted as an economic valuation tool by many federal institutions. Two US federal laws were approved in these years: the Comprehensive Environmental Response, Compensation and Liability Act of 1980, with the purpose of identifying potentially threatened sites and funding their recovery, and its regulatory development of 1986 allowing for the recovery of lost passive-use values and the use of CVM (Portney, 1994). CV was also increasingly applied in Europe. All the previous developments were brought together in an Environmental Protection Agency (EPA) conference in 1984 and they were incorporated in the influential book by Mitchell and Carson (1989). The book included a coherent theoretical framework and put forward the state of the art of the CVM: design issues, elicitation formats, potential biases, etc.

That same year, on 24 March 1989, the Exxon Valdez oil spill occurred in Alaska and, based on the recently developed legislation, the State of Alaska sued the company for the loss of passive-use values. In the words of Carson et al. (2003), "the Exxon Valdez represented the quintessential case in which, to ignore passive use values, was to effectively say that resources that the public had chosen to set aside and not develop could be harmed at little or no cost to the responsible party". On the other hand, the oil industry started a campaign aiming at questioning the reliability of the CVM. Critiques against the CVM were exposed in a conference held in Washington D.C. in March 1992 and sponsored by the Exxon Company (Hausman, 1993). Opponents of the CVM claimed that the reliance on CV surveys in either damage assessments or government decision making was misguided (Diamond and Hausman, 1994). Later that year, the National Oceanic and Atmospheric Administration (NOAA) Blue Ribbon Panel co-chaired by the Nobel Prize awarded Arrow and Solow revised all the theoretical and empirical works on CVM to conclude that: "CV studies can produce estimates reliable enough to be the starting point for a judicial or administrative determination of natural resource damages including lost passive-use value". In addition, the panel established a set of guidelines for CV studies to follow in order to gain reliability. These guidelines were extremely influential in the posterior development of the methodology. The sometimes heated but always healthy debate that occurred in this historical period actually helped enrich the methodology by forcing academics to look deeper into the underlying economic theory and other applied issues. Finally, the acceptance that the CVM has nowadays at both a political and an academic level has boosted the number of applications that are reported every year. 
In order to analyse the state of the art of the CVM, the following section will deal with the theoretical foundations of CV. Issues on survey design will be dealt with in Section 3; the econometrics of CV will be analysed in Section 4; and, finally, Section 5 will provide some concluding remarks. A comprehensive overview of this valuation method can be found in Alberini and Kahn (2006), Carson and Hanemann (2005) and Haab and McConnell (2002).

\section{Economic Theory of Contingent Valuation}

From a welfare economics perspective, public intervention may be justified under the notion of a potential Pareto improvement: that is, if the overall benefits of public intervention exceed its costs. In this context, public intervention may guarantee greater efficiency in resource allocation. However, the sum of social benefits requires, on the one hand, the estimation of an individual's benefits and, on the other hand, aggregating these benefits to the relevant population. The precise measure sought in the process of estimating an individual's benefits is the net change in income that relates to a change in the quality or quantity of a non-market good. That is, precisely, the linkage between the survey instrument and economic theory, because the $\mathrm{CV}$ survey provides information to trace the WTP distribution for a proposed change in an environmental good. CV combines economic theory associated with the structure of the utility function and econometric theory associated with the way that disturbances enter into the process. In fact, the structure of the utility function will be affected by the assumptions made about the distribution of the error component.

CVM obtains an individual's WTP for or willingness to accept (WTA) the change in environmental quality through the survey instrument. The utility theoretical model explained in the introduction to this research provides the basic framework for interpreting the responses to a CV study. Given that these responses are usually treated as random variables, the economic model needs to incorporate a stochastic component and the WTP distributions need to be linked to the survey response probability under the assumption that an individual maximises her utility (Carson and Hanemann, 2005). The cumulative distribution function of WTP, $G_{C}$, and the corresponding probability density function, $g_{C}$, depend on the form of the survey question. In the case of an open-ended question format, where individuals are asked to state their maximum WTP directly, $A$, the probability that the individual's WTP is equal to $A$, is:

$$
\operatorname{Pr}(W T P=A) \equiv g_{C}(A) .
$$

In the case of a closed-ended question format, where individuals are asked whether they would pay a certain amount of money, $A$, the probability that their WTP is equal to or greater than this amount is:

$$
\operatorname{Pr}(W T P \geq A) \equiv 1-G_{C}(A) .
$$

In order to obtain a WTP distribution two approaches have emerged. Early literature based on the open-ended questions format assumes a linear regression on some covariates $(Z \gamma)$ and a normally distributed random term $(\varepsilon)$, so that WTP is also normally distributed: 


$$
W T P=\mu_{W T P}+\varepsilon=Z \gamma+\varepsilon
$$

The second approach incorporates a random term directly into the utility function, in what has been known as random utility models (RUM) (Hanemann, 1984). In the RUM framework, the individual knows with certainty his utility function (this implies that he knows his WTP) but, given that these preferences are not entirely observable to the researcher, they are treated as a random variable, so that the error term is directly included in the (indirect) utility function. Following the closed-ended single-bounded $\mathrm{CV}$ question format, the probability that the respondent answers "yes" can be written as:

$$
\begin{aligned}
& \operatorname{Pr}(y e s)=\operatorname{Pr}\left\{W T P\left(q^{0}, q^{1}, p, y ; \varepsilon\right) \geq A\right\}= \\
& \operatorname{Pr}\left\{v\left(q^{1}, p, y-A ; \varepsilon\right) \geq v\left(q^{0}, p, y ; \varepsilon\right)\right\} \equiv 1-G_{C}(A) .
\end{aligned}
$$

where $q_{0}$ and $q_{1}$ are scalars for the item being valued at the initial (0) and final (1) situations, $p$ is the vector of the prices of the market commodities, $y$ is the person's income and $A$ is the amount of money being offered in the valuation question. Let $\mu_{W T P}=E\left[W T P\left(q^{0}, q^{1}, p, y ; \varepsilon\right)\right], \sigma_{W T P}^{2}=\operatorname{Var}\left[W T P\left(q^{0}, q^{1}, p, y ; \varepsilon\right)\right]$ and let $G(\cdot)$ be the cumulative distribution function of the standardised variate $\omega=\left(W T P-\mu_{W T P}\right) / \sigma_{W T P}$; the probability function can be rewritten as:

$$
\operatorname{Pr}(\text { yes })=1-G\left(\frac{A-\mu_{W T P}}{\sigma_{W T P}}\right) \equiv 1-G(-\gamma+\delta A) \equiv H(A),
$$

where $\gamma=\mu_{W T P} / \sigma_{W T P}$ and $\delta=1 / \sigma_{W T P}$. This expression, where the response to a closedended CV survey is a function of a monetary amount, is consistent with an economic model of maximising behaviour "if and only if it can be interpreted as the survivor function of an economic WTP distribution" (Carson and Hanemann, 2005). The probability model can be parametric or non-parametric as long as the relation between the bid amount and the probability of responding "yes" is non-increasing. The graph showing the response probability function can be considered a demand curve for the change in the environmental good.

In the parametric approach to the specification of a response probability model, the probability of a "yes" response is a known function of the bid amount, while in the non-parametric approach it is treated as an unknown function. Two further differences can be made between the two approaches. Firstly, the non-parametric approach treats the bid levels as separate experiments. Secondly, the non-parametric estimation is capable of obtaining a probability distribution for some points, but in order to obtain welfare measures these points need to be connected. Different ways of connecting these points have been proposed in the literature: linear interpolation (Kriström, 1990), Kaplan-Meier-Turnbull estimation (Carson et al., 2003) or smoothing (Copas, 1983). 


\section{Designing and Administering the Survey Instrument}

\subsection{Survey Design}

The design of the questionnaire is a key issue in CVM given that, as mentioned before, the obtained values are contingent on the information provided. The information provided in the questionnaire should be, on the one hand, consistent with scientific and expert knowledge and, on the other, comprehensible to an average citizen who probably knows little or nothing about the good under valuation. This apparently simple task is complicated because the analyst needs to be trained in survey design, something that economists are not usually trained in. Interested readers may find further details on CV survey design in Mitchell and Carson (1989), Louviere et al. (2000) and Bradburn et al. (2004). In the following, some key features of survey design will be given.

Producing a high quality CV study requires a substantial part of the work to be dedicated to designing the questionnaire. Previous work with scientists and experts, focus groups and in-depth interviews with potential respondents are essential in order to provide a plausible and understandable description of the good under valuation and its context. Feedback from these agents should be used iteratively in the revision of the questionnaire. The development and testing of CV surveys, as with all primary data-collection methods, requires iterative face-to-face pilot testing. Much effort should be devoted to translating expert knowledge into understandable and valuable information for respondents. Face validity is also a desired property of a well-designed survey. It basically means that the information provided in the survey instrument should be clear, accurate and sufficient in order to make a decision and the proposed trade-off plausible.

The current state of practice of CV survey design usually structures the questionnaire in six sections (Carson, 2000):

1. The first section is devoted to introducing the survey purpose, the context for making a decision.

2. The second section provides a clear and detailed description of the good to be valued. This section usually also collects some previous knowledge and attitudes towards the good from the respondents.

3. The third section presents the CV scenario including the current or baseline situation (status quo) and possible future states of the natural resource in the case of no implementation of the proposed policy, including the institutional context in which the good will be provided and the payment vehicle.

4. The fourth section or elicitation section asks for the respondents' maximum WTP to obtain the environmental good or the minimum WTA for giving it up.

5. The fifth section analyses the respondents' understanding and certainty of the answers provided.

6. The last section is devoted to some debriefing questions on the socio-demographic characteristics of the respondents. 
So, in the first place, the researcher needs to evaluate the amount of information needed in order to construct a sufficiently informative and credible questionnaire. This may be especially difficult in cases where prior knowledge about the good in question varies substantially among the relevant population.

Secondly, the core of the CV study is the valuation scenario presented in the questionnaire. The valuation scenario should give clear information on the change to be valued, how it would come about, who would pay for it and how, and other information relevant to considering the change. In developing the survey instrument, the baseline or status quo situation and the outcomes of the proposed policy should be carefully analysed. The elicitation part of the questionnaire provides the researcher with information to estimate the preferences of the individuals.

Several elicitation methods have been proposed (see Table 1). In the open-ended format, respondents are directly asked to state their maximum WTP: "how much would you be willing to pay for this item?" Alternatively, individuals may be presented with a discrete choice question attempting to identify if their true value is lower or higher than a given bid. The simplest form of a discrete choice question is a take-it-or-leave-it offer, which can also be framed as a referendum question. In the dichotomous or closed-ended format, respondents are asked for a yes-no answer to the WTP question: "would you be willing to pay $€ A$ for this item?" In the referendum question format, respondents are usually informed about an environmental programme that would be implemented only if $50 \%$ of the population favours it, in which case all the members of society should pay. The simplicity of the closed-ended question format contrasts with the fact that the estimation of welfare measures is more complicated, the statistical efficiency is lower and the results are sensitive to the model specification (Niklitschek and León, 1996). The elicitation format was extended in the early 1990s to a sequence of paired comparisons or to a single multinomial comparison, also known as a choice experiment. (For a review, interested readers may refer to Hoyos, 2010.)

Efficiency in the elicitation of WTP can be increased if repeated questions are used. In the bidding game format, respondents are iteratively asked to state their maximum WTP: "would you be willing to pay $€ A$ for this item?". If the answer is positive, a new question with a higher value for $\mathrm{A}$ is asked, and if the answer is negative, a new question with a lower value for $\mathrm{A}$ is asked. The bidding game ends when the respondent switches from "yes" to "no" or from "no" to "yes". As opposed to the previous single-bounded format, a double-bounded format has also been proposed in order to overcome the econometric precision that closed-ended questions lose compared with open-ended questions. A variant of the double-bounded approach is the spike model in which, prior to the elicitation question, individuals are asked if they would pay anything (Hanemann and Kanninen, 1999). In order to overcome some problems arising in the double-bounded approach, the one-and-one-half-bounded approach has also been proposed (Cooper et al., 2002). In this case, the second bid is only presented if it is consistent with the respondent's previous answer. Finally, in the payment cards format, respondents face a card with a list of bids (either point estimates or interval ranges) and choose their maximum WTP. 
Table 1

Typology of Elicitation Methods

\begin{tabular}{|l|l|l|}
\hline & Actual WTP obtained & Discrete interval of WTP obtained \\
\hline $\begin{array}{l}\text { Single } \\
\text { question }\end{array}$ & $\begin{array}{l}\text { Open-ended/direct questions } \\
\text { Payment cards } \\
\text { Sealed-bid auction }\end{array}$ & $\begin{array}{l}\text { Take-it-or-leave-it offer } \\
\text { Spending question offer } \\
\text { Interval checklist }\end{array}$ \\
\hline $\begin{array}{l}\text { Iterative } \\
\text { questions }\end{array}$ & $\begin{array}{l}\text { Bidding game } \\
\text { Oral auction }\end{array}$ & $\begin{array}{l}\text { Take-it-or-leave-it offer (with a follow-up } \\
\text { question) }\end{array}$ \\
\hline
\end{tabular}

Source: Mitchell and Carson (1989).

Thirdly, the payment vehicle needs to be credible, coercive and incentive compatible. Another related decision is whether to propose a one-time payment or a recurrent payment. In practice, a one-time payment should be used when the valuation exercise involves a capital investment, while recurrent payment should be used when the provision of the good requires recurrent maintenance.

Fourthly, the analyst should address the bid vector design. Pre-test and pilot studies with open-ended questions can help provide some information on the bounds of respondents' WTP. The bid vector containing four to six levels of the monetary payment is considered reasonably efficient (Carson and Hanemann, 2005).

Finally, the analyst should consider the reliability of the responses and try to minimise the divergence between the stated survey scenario and the respondent's view of this scenario. Gathering information on the motives behind the responses may also help explain the differences encountered in WTP responses. Another related issue is the certainty of respondents regarding the response provided. It is important that the respondent feels that his answer will have policy implications so that he feels comfortable favouring or opposing the proposed policy. For this purpose, questionnaires usually include some reasons to favour or oppose the policy before the valuation question, and at the end of the survey the possibility to revise her answer is sometimes included.

\subsection{Survey Administration}

Another important issue in designing a survey refers to the way it is administered. Some important issues related to the survey administration include the definition of the relevant population, the survey mode, the sampling approach and the sample size. The population of interest is the potential buyers or users of a public good under the circumstances exposed in the CV survey. This is not an easy task so, in practice, two approaches are used: a legal/political perspective, where the relevant population is confirmed by the jurisdiction of the institution financing the $\mathrm{CV}$ study, or a cost-benefit approach, where the relevant population is defined in terms of the costs and benefits of sampling further away from the resource in question.

The public survey may be administered in three ways: mail, telephone or in person. New technologies have also progressively been incorporated in the form of Internet surveys or computer-aided interviews. Obviously, in order to administrate a survey the first thing that the researcher needs to have in mind is the cost of sampling but other 
issues are also important, namely, the capacity of the survey administration mode to account for the relevant population, the different ways in which the stimuli will be presented and the degree of control that the researcher holds over these stimuli. Mail and telephone surveys are cheaper but they have two limitations: visual stimuli cannot be presented and sample selection bias may appear. In-person interviews, on the other hand, are more expensive but they are more flexible and reliable. Finally, computeraided interviews may be helpful for giving visual stimuli or when experimental designs with a high number of choice sets are used.

Sampling approaches may also differ depending on the particular good under valuation. A random sample of the relevant population is best for deriving appropriate inference, but this is not always possible (for example, on-site recreation demand surveys will be affected by sample selection problems). In any case, stratification of the sample increases its efficiency. This stratification strategy is usually based on political boundaries, age, gender, etc. Stratification is usually accompanied by some sort of clustering so that some locations where the survey will be conducted are previously selected in order to reduce the interviewer's travel time and costs. Finally, the sample size should be decided taking into account the level of precision aimed to be achieved and testing the hypotheses of interest.

\section{Econometrics of Contingent Valuation}

In this section, we will focus on modelling the most common elicitation method, the single-bounded closed-ended format questions. More details on the econometrics of CV can be found in Haab and McConnell (2002).

The RUM developed by Hanemann (1984) provides the basic framework for analysing closed-ended single-bounded responses. This approach proceeds by specifying an indirect utility function and a particular distribution for the error component. The indirect utility function for respondent $j$ in state $i$ of the change to be valued ( $i=0$ being the status quo and $i=1$ the final state) can be written as:

$$
u_{i j}=u_{i}\left(y_{j}, z_{j}, \varepsilon_{i j}\right) \text {, }
$$

where $y_{j}$ denotes the respondent's income level, $z_{j}$ is an $m$-dimensional vector of the individual's characteristics including questionnaire variations and $\varepsilon_{i j}$ is the error component. In this case, utility is assumed to arise from income and the presence or absence of the environmental change. It is referred to as the indirect utility function since utility is a function of income and not goods (it is sometimes known as the conditional indirect utility function since utility is conditional on the choice made). Based on this model, the probability of observing a positive response to a specified amount $t_{j}$ would be:

$$
\operatorname{Pr}\left(\text { yes }_{j}\right)=\operatorname{Pr}\left\{u_{1}\left(y_{j}-t_{j}, z_{j}, \varepsilon_{1 j}\right)>u_{0}\left(y_{j}, z_{j}, \varepsilon_{0 j}\right)\right\} .
$$

Parametric estimation of the probability statement above requires two modelling decisions: the functional form of utility and the distribution of the error term. The utility function is generally specified as additively separable in deterministic and stochastic preferences, that is: 


$$
u_{i j}=u_{i}\left(y_{j}, z_{j}, \varepsilon_{i j}\right)=v_{i}\left(y_{j}, z_{j}\right)+\varepsilon_{i j} .
$$

Consequently, the probability of a "yes" response for respondent $j$ becomes:

$$
\operatorname{Pr}\left(\text { yes }_{j}\right)=\operatorname{Pr}\left\{v_{1}\left(y_{j}-t_{j}, z_{j}\right)+\varepsilon_{1 j}>v_{0}\left(y_{j}, z_{j}\right)+\varepsilon_{o j}\right\} .
$$

So, in order to understand the decision to answer positively, the utility difference between the "yes" and "no" states needs to be examined. In other words, the probability of a certain response is examined as a function of the differences in the utilities at the base and final states. Given that the random term can be rewritten as $\varepsilon_{j}=\varepsilon_{1 j}-\varepsilon_{0 j}$, the probability of a positive response is:

$$
\operatorname{Pr}\left(\text { yes }_{j}\right)=1-F_{\varepsilon}\left[-\left(v_{1}\left(y_{j}-t_{j}, z_{j}\right)-v_{0}\left(y_{j}, z_{j}\right)\right)\right],
$$

where $F_{\varepsilon}(a)$ is the probability that the random variable $\varepsilon$ is less than $a$. In the linear utility function specification the deterministic part of a respondent's preferences is linear both in covariates and income:

$$
v_{i j}=\alpha_{i} z_{j}+\beta_{i} y_{j}
$$

where $\alpha_{i}$ denotes an $m$-dimensional vector of parameters, $z_{j}$ is an $m$-dimensional vector of characteristics of the individual including the characteristics of the given $\mathrm{CV}$ scenario, $y_{j}$ is the respondent's discretionary income and $\beta_{i}$ is the marginal utility of income. Denoting by $t_{j}$ the bid vector for the $\mathrm{CV}$ scenario, the deterministic utility for the initial and final state is:

$$
\begin{aligned}
& v_{o j}\left(y_{j}\right)=\alpha_{0} z_{j+} \beta_{0} y_{j} \\
& v_{1 j}\left(y_{j}\right)=\alpha_{1} z_{j+} \beta_{1}\left(y_{j}-t_{j}\right)
\end{aligned}
$$

and assuming that the marginal utility of income is constant in the quality change (i.e. $\beta_{0}=\beta_{1}$ ), the change in deterministic utility for respondent $j$ can be written as:

$$
v_{1 j}-v_{0 j}=\left(\alpha_{1}-\alpha_{0}\right) z_{j}+\beta_{1}\left(y_{j}-t_{j}\right)-\beta_{0} y_{j}=\alpha z_{j}-\beta t_{j},
$$

and the probability of a "yes" response becomes:

$$
\operatorname{Pr}\left(\text { yes }_{j}\right)=\operatorname{Pr}\left(\alpha z_{j}-\beta t_{j}+\varepsilon_{j}>0\right) .
$$

As mentioned before, parametric estimation of the parameters of the change in the utility requires some assumptions about the nature of the random term. The general assumption that $\varepsilon_{j}$ are independently and identically (IID) distributed with mean zero facilitates the wide use of two symmetric distributions: the normal and logistic distributions. In the former, when the error term is thought to be a standard normal random variable, the response function becomes a probit model; in the latter, when the error term is thought to be a logistic random variable, the response function becomes a logit model.

The advantage of the logit model is that it has a closed-form solution, which facilitates its calculation. However, recent computational developments have minimised this difference. From a statistical point of view, both distributions are symmetric, although the logit has thicker tails. It is important to note a fundamental characteristic 
of dichotomous dependent variables: the estimated parameters will always be divided by an unknown variance.

Once the response model to the CV responses is built, a measure of welfare (i.e. people's WTP for the change to be valued) may be estimated. Given that the fitted response model was derived from an underlying WTP distribution, $G_{C}$, the underlying WTP distribution can be recovered from the fitted response model. However, calculating WTP with linear random utility models requires two sources of uncertainty (parameters and preferences) to be taken into account as well as the variability induced by the covariates included in the model.

In dealing with these sources of uncertainty, it is usually assumed that the parameters are given and measures of central tendency over the distribution of preferences are pursued, mainly mean and median WTP. The expression for the expectation of WTP with respect to preference uncertainty is:

$$
E_{\varepsilon}\left(W T P_{j} \mid \alpha, \beta, z_{j}\right)=\frac{\alpha z_{j}}{\beta} .
$$

The median of the distribution of WTP with respect to preference uncertainty is obtained by solving the expression that the probability of final utility greater than initial utility is 0.5 :

$$
M d_{\varepsilon}\left(W T P_{j} \mid \alpha, \beta, z_{j}\right)=\frac{\alpha z_{j}}{\beta} .
$$

So, in the case of linear utility functions and symmetric distributions or error terms, the mean and median WTP are equal. It is important to note that the subscript $j$ for the previous expressions suggests that each respondent has an expected or median WTP with respect to preference uncertainty.

Linear utility models are the most common specification in empirical applications. The only problem with linear utility models is that the marginal utility of income is assumed to be constant across the CV scenarios. In practice, linear models are justified on the grounds that the payment in CV studies usually consists of a very small share of income. Nevertheless, other models allowing differences in income have been proposed: the random utility model log linear in income, the random utility model with Box-Cox transformation in income, etc. Other parametric and non-parametric models for $\mathrm{CV}$ are analysed more deeply in Haab and McConnell (2002).

Some further econometric issues are relevant to the processing of CV data. The first issue refers to the structure of the WTP distributions, given that this is the main output of a CV survey. No matter whether a parametric or a non-parametric approach is adopted, some model specification decisions need to be taken: (1) whether negative WTP values are allowed, (2) the potential existence of corner solutions (spike at zero WTP), (3) how to ensure weak monotonicity of the WTP distribution to increases in the monetary amount, (4) the smoothness of the WTP distribution as it departs from zero and (5) how to deal with the right-hand tail of the WTP distribution (Carson and Hanemann, 2005).

A second issue concerns the bid design, that is, the set of bids that will be randomly assigned to respondents. The optimal bid design should have as many design points placed along the cost space as model parameters. Usually, these points are placed so as to maximise the determinant of the information matrix in what is known as a D-optimal criterion (Cooper, 1993). Alternatively, given that our welfare estimate of interest is the 
ratio of two parameters, C-optimal designs have also been proposed with the objective of minimising the confidence interval for the mean WTP (Alberini, 1995). Other proposed designs include Bayesian designs, minimax designs and sequential designs (Vasquez et al., 2007). In practice, the model parameters are unknown so the bid vector used in a CV survey is generally obtained from pre-test and pilot studies. Four to six bid points produces reasonably efficient and robust estimates (Carson and Hanemann, 2005).

Another frequent empirical problem relates to the treatment of don't knows and protest answers. It is clear that the uncertainty of the respondent about the answer to a $\mathrm{CV}$ study provides low quality data and that is the main reason why the Blue Ribbon Panel recommended including a "don't know" option in addition to the typical referendum question (Arrow et al., 1993). However, recent literature on this issue has shown that allowing for a "don't know" option does not significantly affect the quality of the survey responses but it reduces substantially the amount of information collected. In any case, these answers need to be econometrically treated and three options are available: exclude these answers from the data set, recode them as "no" responses or impute them using some specific model. Dropping "don't know" answers is equivalent to allocating them proportionally into positive/negative responses. Nevertheless, Carson et al. (1998) analyse in depth the issue on voting uncertainty, concluding that these answers tend to be "no" responses and so they would be better treated as negative answers. Protest zeros, on the other hand, are those answering "no" but a follow-up question on the reasons for this answer suggests that they might have some positive WTP. Typically protest answers are those claiming that the government or the one causing the damage should pay for its recovery. These answers are usually dropped from the data but some authors argue that given the context-specific nature of the CV survey these respondents would more probably vote against the proposed policy and they are better treated as "no" responses (Carson and Hanemann, 2005). It is important to note that recoding "don't know" answers and protest zeros as "no" responses provides more conservative estimates of WTP, which might be interesting from a policy perspective. Sample selection models have also been proposed in order to take into account both zero values and protest answers in the model estimates (Strazzera et al., 2003).

Uncertainty may also be specifically treated in analysing responses to CV surveys. The identification and treatment of respondent uncertainty is also a new trend in environmental valuation. Carson and Hanemann (2005) encounter some problems in the introduction of an extra source of uncertainty into CV statistical models: firstly, there is no room for adding an extra source of uncertainty in the RUM model without adding more structure to the model; secondly, identifying the extra source of uncertainty by modifying the utility function is complicated because parametric models already allow for some form of deviation; and thirdly, identifying the extra source of uncertainty by including a typically Likert psychometric scaled question is potentially difficult. Allowing for heterogeneity in the error component may be another way of approaching these phenomena. Finally, parametric and non-parametric approaches are used to test for differences in WTP distributions due to scope. More recently, convolutions and bootstrap approaches have been applied (Poe et al., 2005).

Validity and reliability have been the centre of the debate between proponents and opponents of the CVM. Validity refers to the extent to which what one wishes to measure corresponds to what was actually measured, i.e. a measure of accuracy. Reliability, on the other hand, refers to the replicability of the obtained results. Testing validity is difficult 
because, given that the maximum WTP is inherently unobservable, there is no correct measure for results to be compared with. As a consequence, validity is usually determined through construct validity (sometimes referred to as internal validity) and convergence validity (sometimes referred to as external validity). Construct validity tests compare the consistency of the measurement made with factors, such as economic theory, while convergence validity tests compare the measurement made with the results of a different valuation technique. Reliability is usually tested in two ways: the stability of WTP measures over time and test-retest reliability, where a sample of respondents is interviewed twice with the same survey instrument.

\section{Conclusions}

The literature on CV since the early 1960s is vast. Carson (2007) collects over six thousand papers from one hundred countries in fifty years of CV history. Such a large amount of applications allows us to extract two conclusions about the state of the art of the method: on the one hand, despite some interesting debates in the 1990s, $\mathrm{CV}$ is generally accepted at both an academic and a political level; and, on the other, difficulties in discriminating the nature and the quality of the survey instrument make any general valid statement about the properties of CVM impossible. In any case, the controversies surrounding the use of CVM have actually promoted "the most serious investigation of individual preferences ever undertaken in economics" (Carson et al., 2001).

Almost fifty years of CVM have provided a strong theoretical and empirical basis, although there is room for refinement in the coming years. Many of the critics have been proved to be erroneous while others, being correct, are not CV specific but rather inherent problems of the neoclassical framework. The theoretical inconsistency of empirical CV results have mainly been due to incorrectly transferring the theoretical framework for price changes to the imposed quantity changes that characterise most environmental goods and services. However, as Carson and Hanemann (2005) point out, welfare estimation with stated preference methods requires a correct understanding of the differences between private and public goods:

Public goods are a special case of quantity rationed goods and, as a result, the focus should be on a quantity space with an inverse demand system rather than price space with an ordinary demand system where consumers are free to choose their optimal consumption levels.

The main challenge posed to economists by the widespread use of CVM refers to the correct design of the questionnaire, given the fact that they are not usually trained in this matter. A reliable CV survey is complicated to design and expensive to administrate but, as Carson et al. (2001) argue, many of the alleged problems with CVM may be solved by careful design and administration. CV surveys should be properly and carefully conducted and they should include internal consistency tests so that the validity and reliability of the results can be further tested.

The main advantage posed by the use of CVM in environmental economics has been its ability to measure the benefits of environmental changes in a large amount of situations. It can also aid at public decision making by better understanding the good under valuation and individuals' preferences for this good. Acknowledging the imprecision of obtained welfare measures, it may still be more dangerous to leave public decision making in the 
hands of politicians or "experts". While experts may determine the physical damages or the costs of restoration of a natural resource, only the public can assess what this change is worth. In the words of Hanemann (1994): "when the public valuation is the object of measurement, a well-designed $C V$ survey is one way of consulting the relevant experts, the public itself'.

\section{References}

Alberini, A. (1995), "Optimal Designs for Discrete Choice Contingent Valuation Surveys: Single-Bound, Double-Bound, and Bivariate Models." Journal of Environmental Economics and Management, 28, pp. 287-306.

Alberini, A., Kahn, J. (2006), Handbook on Contingent Valuation. Cheltenham, UK: Edward Elgar.

Aldy, J., Krupnick, A. (2009), "Introduction to the Frontiers of Environmental and Resource Economics." Journal of Environmental Economics and Management, 57, pp. 1-4.

Arrow, K., Fisher, A. C. (1974), "Environmental Preservation, Uncertainty and Irreversibility." Quarterly Journal of Economics, 88, pp. 313-319.

Arrow, K. et al. (1993), "Report of NOAA Panel on Contingent Valuation." Federal Register, 58, pp. 4601-4614.

Bishop, R., Heberlein, T. (1979), "Measuring Values of Extramarket Goods: Are Direct Measures Biased?" American Journal of Agricultural Economics, 61, pp. 926-930.

Bowen, H. R. (1943), "The Interpretation of Voting in the Allocation of Economic Resources." Quarterly Journal of Economics, 58, pp. 27-48.

Bradburn, N., Sudman, S., Wansink, B. (2004), Asking Questions: The Definitive Guide to Questionnaire Design. San Francisco: Jossey-Bass.

Cameron, T. A. (1988), "A New Paradigm for Valuing Non-Market Goods Using Referendum Data: Maximum Likelihood Estimation by Censored Logistic Regression." Journal of Environmental Economics and Management, 15, pp. 355-379.

Cameron, T. A., James, M. D. (1987), "Efficient Estimation Methods for 'Close-Ended' Contingent Valuation Surveys." The Review of Economics and Statistics, 69, pp. 269-276.

Carson, R. T. (2000), "Contingent Valuation: a User's Guide." Environmental Science \& Technology, 34, pp. 1413-1418.

Carson, R. T. (2007), Contingent Valuation: A Comprehensive Bibliography and History. Cheltenham: Edward Elgar.

Carson, R. T., Hanemann, W. M. (2005), "Contingent Valuation," in Mäler, K. G., Vincent, J. R., ed., Handbook of Environmental Economics. Valuing Environmental changes. Vol. 2. Amsterdam: Elsevier, pp. 821-936.

Carson, R. T., Flores, N., Meade, N. F. (2001), "Contingent Valuation: Controversies and Evidence." Environmental and Resource Economics, 19, pp. 173-210.

Carson, R. T. et al. (1998), "Referendum Design and Contingent Valuation: the NOAA Panel's No Vote Recommendation." Review of Economics and Statistics, 80, pp. 484-487.

Carson, R. T. et al. (2003), "Contingent Valuation and Lost Passive Use: Damages from the Exxon Valdez Oil Spill." Environmental and Resource Economics, 25, pp. 257-286.

Ciriacy-Wantrup, S. V. (1947), "Capital Returns from Soil-Conservation Practices." Journal of Farm Economics, 29, pp. 1181-1196.

Ciriacy-Wantrup, S. V. (1952), Resource Conservation: Economics and Policy. Berkeley: University of California Press. 
Cooper, J. C. (1993), "Optimal Bid Selection for Dichotomous Choice Contingent Valuation Surveys." Journal of Environmental Economics and Management, 24, pp. 25-40.

Cooper, J. C., Hanemann, W. M., Signorello, G. (2002), "One-And-One-Half-Bound Dichotomous Choice Contingent Valuation." The Review of Economics and Statistics, 84, pp. 742-750.

Copas, J. B. (1983), "Plotting p against x." Applied Statistics, 32, pp. 25-31.

Davis, R. K. (1963a), "Recreation Planning as an Economic Problem." Natural Resources Journal, 3 , pp. 239-249.

Davis, R. K. (1963b), "The Value of Outdoor Recreation: An Economic Study of the Maine Woods." Dissertation, Harvard University.

Diamond, P. A., Hausman, J. A. (1994), "Contingent Valuation: Is Some Number Better than No Number?" The Journal of Economic Perspectives, 8, pp. 45-64.

Haab, T. C., McConnell, K. E. (2002), Valuing Environmental and Natural Resources. The Econometrics of Non-Market Valuation. Cheltenham, UK: Edward Elgar Publishing Limited.

Hanemann, W. M. (1984), "Welfare Evaluations in Contingent Valuation Information with Discrete Responses." American Journal of Agricultural Economics, 66, pp. 332-341.

Hanemann, W. M. (1994), "Valuing the Environment through Contingent Valuation." The Journal of Economic Perspectives, 8, pp. 19-43.

Hanemann, W. M., Kanninen, B. J. (1999), "The Statistical Analysis of Discrete-Response CV Data," in Bateman, I. J., Willis, K. G., eds., Valuing Environmental Preferences. Oxford: Oxford University Press, pp. 302-441.

Hausman, J. (1993), Contingent Valuation: A Critical Assessment. Amsterdam: North-Holland.

Hoyos, D. (2010), "The State of the Art of Environmental Valuation with Discrete Choice Experiments." Ecological Economics, Vol. 69, pp. 2372-2381

Knetsch, J. L., Davis, R. K. (1966), "Comparisons of Methods for Resource Evaluation," in Kneese, A. V., Smith, S. C., eds., Water Research. Baltimore: John Hopkins University Press, pp. 125-142.

Kriström, B. (1990), "A Nonparametric Approach to the Estimation of Welfare Measures in Discrete Response Valuation Studies." Land Economics, 66, pp. 135-139.

Krutilla, J. V. (1967), “Conservation Reconsidered.” American Economic Review, 57, pp. 777-786.

Louviere, J., Hensher, D. A., Swait, J. (2000), Stated Choice Methods: Analysis and Applications. Cambridge: Cambridge University Press.

McConnell, K. E. (1990), "Models for Referendum Data: the Structure of Discrete Choice Models for Contingent Valuation." Journal of Environmental Economics and Management, 18, pp. 19-34.

Mitchell, R. C., Carson, R. T. (1989), Using Surveys to Value Public Goods: The Contingent Valuation Method. Washington, D.C.: RFF Press.

Niklitschek, M., León, J. (1996), "Combining Intended Demand and Yes/No Responses in the Estimation of Contingent Valuation Models." Journal of Environmental Economics and Management, 31, pp. 387-402.

Poe, G. L., Giraud, K. L., Loomis, J. B. (2005), "Computational Methods for Measuring the Difference of Empirical Distributions." American Journal of Agricultural Economics, 87, pp. 353-365.

Portney, P. R. (1994), "The Contingent Valuation Debate: Why Economists Should Care." The Journal of Economic Perspectives, 8, pp. 3-17.

Strazzera, E. et al. (2003), "Modelling Zero Values and Protest Responses in Contingent Valuation Surveys." Applied Economics, 35, pp. 133-138.

Vasquez, F., Cerda, A., Orrego, S. (2007), Valoración Económica del Ambiente. Buenos Aires: Thomson.

Weisbrod, B. A. (1964), "Collective Consumption Services of Individual Consumption Goods." Quarterly Journal of Economics, 78, pp. 471-477. 